\title{
An Historical Analysis of the Taylor Curve
}

\author{
Eric Olson \\ Pepperdine University \\ Malibu, CA 90263-4237 \\ eolson@pepperdine.edu \\ Walter Enders* \\ Department of Economics and Finance \\ Culverhouse College of Commerce \& Business Administration \\ University of Alabama \\ Tuscaloosa, AL 35487-0024 \\ wenders@cba.ua.edu
}

March 5, 2012

\begin{abstract}
Taylor (1979) shows that there is a permanent tradeoff between the volatility of the output gap and the volatility of inflation. Although a number of papers argue that the so-called Taylor curve is a policy menu, Friedman (2006) points out that it is more likely to serve as an efficiency locus that can be used to gauge the appropriateness of monetary policy. Using data from 1875 onward, we examine the efficiency of U.S. monetary policy by measuring the orthogonal distance between the observed volatilities of the output gap and inflation from the Taylor curve. In addition, we identify time periods in which the variability of the U.S. economy changed by observing shifts in this efficiency frontier.
\end{abstract}

*Corresponding author.

JEL classifications: E31, E58, C32

Key words: Monetary Policy, Taylor Principle, Phillips Curve, Optimal Control 


\section{Introduction}

In much of the older macroeconomics literature, the Phillips curve relationship was used to depict the dilemma faced by a central bank trying to attain the goals of price stability and high employment. The "policy menu" represented by the Phillips curve necessitated that a central bank trying to promote either one of these objectives had to accept a deterioration of the other. More recently, Taylor (1979) developed a "second order" Phillips curve allowing for a permanent trade-off between the second moments of the Phillips curve variables. As argued by Chatterjee (2002), the so-called Taylor curve is consistent with the modern macroeconomic view that central banks cannot systematically increase the level of output but can stabilize the variance of output. The trade-off is particularly acute in the presence of supply shocks since a central bank cannot simultaneously reduce the variance of output and inflation.

Taylor (1979) and Friedman (2006) point out that the Taylor curve can be viewed as an efficiency locus in that the actual variances of output and inflation can exceed the values lying on the Taylor curve. After all, in Friedman's well-known view, monetary policy was suboptimal for relatively long periods of time in the sense that the Federal Reserve often exacerbated macroeconomic instability. Moreover, since the Taylor curve is unobservable, discrepancies could result whenever the central bank incorrectly perceives the location of the curve. It is also likely that large and unanticipated economic shocks would result in discrepancies from the Taylor curve. Whatever the cause, these discrepancies can be persistent if the central bank has objectives other than minimizing inflation and output variability. For example, if the central bank is concerned with interest rate smoothing, it might be loath to substantially adjust interest rates even in the presence of high inflation and/or output variability. 
The aim of the paper is to show that it is possible to use the Taylor curve as a lens through which to gauge the deviations of actual U.S. monetary policy from the optimum. Unlike structural DSGE models, such as that by Ravenna (2009), our estimation of an optimal frontier does not rely on model-specific assumptions. In Sections 2 and 3 we explain the nature of the Taylor curve and show how it can be estimated using a long historical data set. In Section 4 we estimate rolling VARs using data spanning the 1875 - 2009 time period and use the estimated parameters to construct the corresponding Taylor curves. We characterize the historical efficacy of monetary policy by calculating the minimum orthogonal distance between the observed volatilities of inflation and the output gap from the appropriate Taylor curve.

Of course, the position of the Taylor curve can change over time. A key determinant of the location of the curve is the variability of the underlying aggregate demand and supply shocks. The smaller (larger) the size of the shocks the economy experiences the closer (further) the efficiency frontier will be to the origin. For example, the well documented decline in the variance of most macroeconomic variables since the mid-1980s implies that the Taylor curve has shifted towards the origin. In Section 5, we report the Taylor curves estimated for a number of key historical periods as well as the time-series of the orthogonal distances of the Taylor curve from the origin. We show how the location of the Taylor curve has evolved over time and how changes in the slope have altered the opportunity cost of stabilizing inflation relative to output. Our conclusions are contained in section 6.

\section{The Derivation of the Taylor rule and the Taylor curve}

Consider a central bank with the loss function $(L)$ that depends on the squared deviations of output and inflation from their target levels:

$$
L=\lambda\left(\pi_{t}^{a}-\pi_{t}^{*}\right)^{2}+(1-\lambda)\left(y_{t}^{a}-y_{t}^{*}\right)^{2}
$$


where $\lambda$ is the central bank's preference for inflation stability, $\pi_{t}^{a}$ is the actual inflation rate, $\pi_{t}^{*}$ is the target inflation rate, $y_{t}^{a}$ is actual output, and $y_{t}^{*}$ is level of potential output. For notational simplicity, let the deviation of inflation from its target level be denoted by $\pi_{t}$ and let the output gap, $y_{t}^{a}-y_{t}^{*}$, be denoted by $y_{t}$.

The derivation of the Taylor curve is essentially the same as that used to derive the Taylor rule. Given the central bank's loss function and the structural equations that govern the time paths of $y_{t}$ and $\pi_{t}$, Taylor (1979) shows how to derive the feedback rule (i.e., the Taylor rule) relating the federal funds rate $\left(i_{t}\right)$ to the current state of the economy. In the simplest case, the central bank selects a rule of the form $i_{t}=w y_{t}+(1-w) \pi_{t}$ where the selection of the weight $w$ minimizes the expected value of (1). Since the derivation can be found in many graduate macroeconomic texts, such as Woodford (2003), we do not repeat it here. Instead, we point out that the selected value of $w$ depends on the central bank's preference for inflation stability $(\lambda)$. As such, the resulting optimized values of the variances of inflation and the output gap depend on $\lambda$. By varying $\lambda$, it is possible to plot an efficiency frontier, such as the Taylor curve $T_{1} T_{1}$ depicted in Figure 1a, as the locus of points indicating the smallest variance of inflation obtainable for any given variance of the output gap.

Monetary policy that is optimal would result in the economy operating on its efficiency frontier at a point such as $A$ in Figure 1a. Sub-optimal policy would result in the observed volatilities lying above the Taylor curve at a point such as $B$. Clearly, movements towards the Taylor curve represent an improvement in monetary policy. ${ }^{1}$ Shifts in the Taylor curve itself, such as a movement from Taylor curve $T_{1} T_{1}$ to $T_{2} T_{2}$, result from changes in the variability of the

\footnotetext{
${ }^{1}$ Without actually estimating any Taylor curves, Lee (2002) argues that most movements occur along a Taylor curve whereas Friedman (2006) and Olson, Enders and Wohar (2012) argue that the movements are generally like those between points between $A$ and $B$.
} 
shocks that the economy experiences. Of course, the curvature of the Taylor curve is also important because it represents the cost of stabilizing inflation volatility in terms of output gap volatility. Consider Figure 1b. At point $A$, the slope of the curve $T_{3} T_{3}$ is clearly steeper than that of $T_{4} T_{4}$. A central bank at $A$ wishing to reduce inflation volatility will have to tolerate greater output volatility if it faces $T_{3} T_{3}$ than $T_{4} T_{4}$.

\section{[Insert Figure 1a and 1b here]}

\section{Estimating the Taylor Curve}

\subsection{The VAR}

In order to obtain the structural parameters necessary for construction of a Taylor curve, we rely on a vector autoregression (VAR) that is a variant of the aggregate demand and supply model developed in Mishkin and Schmidt-Hebbel (2007). Consider:

$$
\begin{aligned}
& y_{t}=\alpha_{1,0}+\sum_{\mathrm{i}=1}^{\mathrm{n}} \alpha_{1, i} y_{t-i}+\sum_{\mathrm{i}=1}^{\mathrm{n}} \beta_{1, i} \pi_{t-i}+\sum_{\mathrm{i}=1}^{\mathrm{m}} \phi_{1, i} i_{t-i}+\varepsilon_{1, t} \\
& \pi_{t}=\alpha_{2,0}+\sum_{\mathrm{i}=1}^{\mathrm{n}} \alpha_{2, i} y_{t-i}+\sum_{\mathrm{i}=1}^{\mathrm{n}} \beta_{2, i} \pi_{t-i}+\sum_{\mathrm{i}=1}^{\mathrm{m}} \phi_{2, i} i_{t-i}+\varepsilon_{2, t}
\end{aligned}
$$

Equation (2) represents a reduced form model of the output gap $\left(y_{t}\right)$ as a function of its own lags, lags of the nominal interest rate $\left(i_{t}\right)$, and lags of the difference between the inflation rate and its target $\left(\pi_{t}\right)$. The lag length, $n$, is the same for $y_{t}$ and $\pi_{t}$ both equations and the lag length for the interest rate, $m$, can differ from $n$. Equation (3) represents a reduced form model of the Phillips curve, in which our measure of inflation is a function of its own lags, lags of the output gap, and lags of the nominal interest rate $\left(i_{t}\right)$.

In order to estimate a VAR in the form of (2) and (3), we obtained data from Balke and Gordon (1988) for the period 1875Q1-1947Q1 and from the St. Louis FRED database for 1947Q1 - 2009Q3. The data were spliced together such that values of real and nominal GNP in 
the Balke and Gordon (1988) data set for 1947Q1 matched the corresponding 1947Q1 values in the St. Louis FRED database. We were able to extend the Balke and Gordon (1988) interest rate series (i.e., the 6-month commercial paper rate) through 1983Q4. However, due to the lack of data after 1983, we used the 6-Month Treasury Constant Maturity Rate from the FRED database for the 1984Q1-2009Q3 time period. We measure the output gap as the difference in the log of real GNP from an Hodrick-Prescott (HP) filter and our measure of inflation is the log of the yearto-year difference of the GNP deflator less an HP trend. Note that this series tracks FRED's Consumer Price Index for All Urban Consumers: All Items (CPIAUCNS) quite well even during the turbulent 1920s.

Even though the HP filtered series should be stationary, as a precaution, we performed standard augmented Dickey-Fuller tests to determine whether or not the variables are stationary. All transformed variables in (2) and (3) were found to be stationary at the 5\% significance level. The lag length of the VAR was obtained using the general-to-specific methodology beginning with a maximum of nine quarterly lags of $y_{t}$ and $\pi_{t}$ and no less than two lags of $i_{t}$. Paring down the model proceeded by using LM tests for a prob-value of $5 \%$.

\subsection{Constructing the Taylor Curve}

In constructing the Taylor curve we follow the methodology detailed in Taylor (1979) and in Cecchetti, Flores-Lagunes, and Krause (2006). The optimization procedure is best described by rewriting the structural model of (2) - (3) in its state-space representation. Since we are interested in the variances, we can ignore the intercept terms and write

$$
Y_{t}=B Y_{t-1}+c i_{t-1}+v_{t}
$$

where $\mathbf{i}_{\boldsymbol{t}-\mathbf{1}}$ is a scalar and 


$$
\mathbf{Y}_{\mathbf{t}}=\left[\begin{array}{c}
\mathrm{y}_{t} \\
\vdots \\
\mathrm{y}_{t-8} \\
\pi_{t} \\
\vdots \\
\pi_{t-8} \\
\mathrm{i}_{t-1}
\end{array}\right] \mathbf{B}=\left[\begin{array}{ccccccc}
\alpha_{11} & \cdots & \alpha_{19} & \beta_{11} & \cdots & \beta_{19} & \emptyset_{12} \\
1 & 0 & \cdots & \cdots & \cdots & \cdots & 0 \\
0 & \ddots & \cdots & \cdots & \cdots & \cdots & 0 \\
\alpha_{21} & \cdots & \alpha_{29} & \beta_{21} & \cdots & \beta_{29} & \emptyset_{22} \\
0 & \cdots & \cdots & \ddots & \cdots & \cdots & 0 \\
0 & \cdots & \cdots & \cdots & \ddots & \cdots & 0 \\
0 & \cdots & \cdots & \cdots & \cdots & 1 & 0
\end{array}\right] \mathbf{c}=\left[\begin{array}{c}
\varnothing_{11} \\
0 \\
\vdots \\
\varnothing_{22} \\
0 \\
\vdots \\
1
\end{array}\right] \quad \mathbf{v}_{\boldsymbol{t}}=\left[\begin{array}{c}
\varepsilon_{1 t} \\
0 \\
\vdots \\
\varepsilon_{2 t} \\
0 \\
\vdots \\
0
\end{array}\right]
$$

In matrix notation, the loss function in (1) can be as:

$$
\mathbf{Y}_{\mathrm{t}}^{\prime} \Lambda \mathbf{Y}_{\mathrm{t}}
$$

where $\Lambda$ is a square weighting matrix with the first diagonal element equal to $\lambda$, the tenth diagonal element equal to $(1-\lambda)$, and the remaining elements equal to zero. The objective of the central bank is to pick the interest rate path which minimizes (6) subject to the constraints of the economy imposed by (4). Given the quadratic nature of the loss function, the solution for the interest rate will be linear which is written as:

$$
\mathbf{i}_{\mathbf{t}}=\mathbf{g} \mathbf{Y}_{\mathrm{t}-1}
$$

The control vector $\mathbf{g}$ in the steady state is found using optimal control techniques and given by:

$$
\mathbf{g}=-\left(\mathbf{c}^{\prime} \mathbf{H c}\right)^{-1} \mathbf{c}^{\prime} \mathbf{H B}
$$

where $\mathbf{H}$ is the solution of the equations ${ }^{2}$

$$
\mathbf{H}=\boldsymbol{\Lambda}+(\mathbf{B}+\mathbf{c g})^{\prime} \mathbf{H}(\mathbf{B}+\mathbf{c g}) .
$$

Given the estimated values of the parameters in $\mathbf{B}$ and $\mathbf{c}$, we can solve $\mathbf{H}$ and $\mathbf{g}$ for any value of $\lambda$. For a given set of feedback coefficients, $\mathbf{g}$, the stochastic component of $\mathbf{Y}_{\mathbf{t}}$ is described by (7). Thus, the steady state covariance matrix of $\mathbf{Y}_{\mathbf{t}}$ is given by $\boldsymbol{\Sigma}$ which satisfies

$$
\Sigma=\Omega+(B+\mathbf{c g})^{\prime} \Sigma(B+\mathbf{c g})
$$

\footnotetext{
${ }^{2}$ See Chow (1975) for a further discussion of the mechanics of this type of control problem.
} 
where $\mathbf{\Omega}$ is the covariance matrix of the residuals in $\mathbf{V}$. The first and the tenth diagonal elements of $\boldsymbol{\Sigma}$ contain the steady-state variances. Given a particular weight to inflation stability, $\lambda$, this procedure determines a single point on the Taylor curve. By varying the weight assigned to inflation over the $[1,0]$ interval, an entire Taylor curve can be traced out. ${ }^{3}$

Before proceeding it is necessary to point out a number of implicit assumptions in our estimation methodology. Notice that in (1), the central bank has a time-invariant loss function that does not exhibit the type of interest rate smoothing considered by Rudebusch (2002) and Woodford (1999). Whenever the central bank is reluctant to change the interest rate, discrepancies from the Taylor curve can be persistent. Moreover, in contrast asymmetric loss functions considered by Dolado, Maria-Dolores, and Naveira (2005) and Bunzel and Enders (2010), the central bank does not value positive discrepancies from targets differentially from negative ones. Clearly, the values of $\pi_{t}^{*}$ and $y_{t}^{*}$ are not observable and our methodology assumes that they are reasonably captured by the HP filter.

\subsection{Constructing the Taylor Curve through Time}

Experimentation indicated that a moderately large sample size, $T$, of about 150 observations is needed to obtain relatively stable estimates of the Taylor curve. However, since we wanted to obtain results for the early portion of our sample period, we report results using an expanding window until 1912Q3 and a rolling window thereafter. Specifically, we estimate the VAR as in Section 3.1 for the first 100 usable observations, select the lag lengths using the general-to-specific method described above, and subsequently derive the Taylor curve by implementing the procedure outlined in Section 3.2. Given this efficiency frontier, we calculate

\footnotetext{
${ }^{3}$ While such optimal control techniques are certainly subject to the Lucas critique, the empirical significance of the Lucas critique is an unsettled issue. A number of authors argue that the critique is logically correct, but find that changes in monetary rules have little effect on estimated VARs. See Favero and Hendry (1992), Hendry (2000), Estrella and Fuhrer (1999), and Ericsson and Irons (1995) for further discussion. Below, we address the issue by estimating Taylor curves for a number of subsamples and by using a rolling window.
} 
the minimum orthogonal distance between the observed volatilities for the 1877Q3 - 1902Q2

period and their optimal values. The above calculations are then repeated by adding one additional quarter of data until we reach a sample size such that $T=150$. Thereafter, we proceed by using a rolling window of 150 observations until we reach $2009 \mathrm{Q} 3 .{ }^{4} \mathrm{We}$ consider the distance measures in Section 4 and the location of the Taylor curve in Section 5.

\section{Distance from the Taylor Curve}

Figure 2 displays the time series of the derived minimum distance along with a confidence band of \pm 1.64 standard deviations. The confidence bands are obtained by first estimating the VAR for the up through 1900Q1 and obtaining the orthogonal distance of the actual variances of output and inflation from the estimated Taylor curve. Next, in order to determine the importance of measurement error in the variables, we augment each observation of each variable by a random noise term. The resulting variables are then scaled in such a way as to maintain each of the variable's conditional mean and conditional variance. We apply the methodology of Section 4.2 to this simulated sample in order to obtain a simulated minimum distance for this first period. Repeating this resampling process 250 times enables us to obtain a simulated ninety percent confidence interval for the first minimum distance measure. By incorporating the successive quarterly observations into the rolling window as in Section 4.3, it is possible to obtain the confidence interval for the entire sample. ${ }^{5}$ Notice that the lower confidence band for the orthogonal distances is allowed to be negative since the actual variances of output and inflation can lie below the simulated Taylor curves.

\footnotetext{
${ }^{4}$ In an earlier version of the paper, we reported a relative distance measure to account for shifts in the Taylor curve. In essence, we divided the minimum orthogonal distance between the observed volatilities and the Taylor curve by the minimum distance of the Taylor curve to the origin. We also performed the entire analysis using an expanding window instead of a rolling window. Both sets of results are available in the Unpublished Appendix tot his paper.

${ }^{5}$ For the construction of the distance measure, we use every observation in the sample. However, since the simulation for construction of the confidence interval takes a long time to compute, we construct the interval for the first quarter of each year and interpolate the points for the intervening quarters.
} 
Notice that the figure suggests four distinct episodes that correspond to the practice of monetary policy.

\subsection{The Gold Standard}

The time period before the establishment of the Federal Reserve in 1914, commonly regarded as the international gold standard era, included 11 business cycles, deflation at the turn of the century, and one substantial financial crisis in $1907 .{ }^{6}$ For our purposes, this period serves as a benchmark since it predates the creation of the Federal Reserve. Even though most of this subsample is estimated using less than 150 observations, Figure 2 indicates that our distance measures from the Taylor curve were reasonably stable throughout the period until the early 1920s.

\subsection{The Interwar Period}

The interwar period experienced 5 business cycles and two periods of deflation: one the early 1920s and the other in the early 1930s. Although the Federal Reserve was formed in 1914, WWI largely kept policy makers from pursuing active policy until early in the 1920s. Much of the early policy was used in aiding the Treasury to keep borrowing costs low and represented an era in which policy makers could focus on developing an interventionist monetary policy. In Figure 2, note the movement away from the efficiency frontier corresponding to the beginning of this activist policy. The clear implication is that, relative to the Gold Standard period, monetary policy was sub-optimal throughout much of the 1920s. As discussed by Orphanides (2003), during this period monetary policy was so loose that there was speculative use of Federal Reserve credit in the stock market.

Interestingly, the relatively tight monetary policies in the early 1930 s appear to have moved the economy towards the efficiency frontier. As can be seen in Figure 2, the minimum

\footnotetext{
${ }^{6}$ The cycles are counted using the NBER dates.
} 
distances were quite low throughout the 1930s. ${ }^{7}$ Nevertheless, as discussed in Goodfriend (1991), it could be argued that monetary policy was essentially inactive during this time period due to short-term interest rates being near zero (or pegged to ensure low borrowing costs for Treasury). As also shown in Figure 2, the distance measures remain stable until the beginning of WWII (when they rise slightly) and then exhibit a huge jump after the war.

\subsection{The Treasury Accord through the mid-1980s}

It is possible to date the resumption of active policy by the Federal Reserve with the adoption Treasury-Federal Reserve Accord in 1951. This period witnessed five business cycles, the Korean and Vietnam wars, the collapse of the Bretton Woods system, and the era of Great Inflation. If one equates active monetary policy with attempts to fine-tune the economy, the beginning of active policy in the 1920 and resumption in the 1950s, are clearly associated with large distances of the economy from the Taylor curve.

Clarida, Gali, and Gertler (2000) documented several serious flaws embedded in the monetary policy rules of the 1970 s. It is claimed that the failure to follow the so-called Taylor Principle contributed to the easy money of the 1970s. Moreover, fears of sustained increases in the unemployment rate are equivalent to a reduction in the Federal Reserve's preference towards price stability. In fact, Taylor (1998) argues that much of the cause of the Great Inflation was due to excessively loose monetary policy resulting from the above mentioned policy flaws and the collapse of the Bretton Woods system. Nevertheless, not all macroeconomists share this interpretation. Orphanides (2003) suggests that the policies pursued during the Great Inflation were not inherently flawed. Rather, the poor policy was a result of inaccurate measures of potential output which led to inappropriate policy prescriptions. The key point is that we find that

\footnotetext{
${ }^{7}$ See Orphanides (2003) for a much more in depth discussion regarding the policy leading up the Great depression. $\mathrm{He}$ argues that the Federal Reserve tightened policy as it began to pursue a policy similar to that of a Taylor rule.
} 
the minimum distances do begin to increase in the mid-1960s, dip in the early 1970s, and then jump and remain high until the early 1980s.

\subsection{The Great Moderation to the Great Recession}

In this period, the economy experienced 5 business cycles, the two Iraq Wars, the beginning of the War on Terrorism, and one substantial financial crisis. As shown in Figure 2 there was a sharp decline in the distance measures shortly after the start of Paul Volker's tenure as Federal Reserve Chairman. This period, corresponding to the Great Moderation, saw a decline in the economy's distance from the Taylor curve. By the mid-1980s, the distance stabilized at a level approximating the one prevailing during the gold standard period. (As we show below, the Taylor curve moved toward the origin so that the decline in the distance implies that the economy moved towards the Taylor curve more than the Taylor curve shifted towards the origin.) Thus, we support the widely held view that the performance of monetary policy clearly improved in the early 1980s. In particular, it is quite possible that the increased weight assigned to inflation was crucial in taming inflationary expectations and mitigating their self-fulfilling nature. Moreover, the predictability of short-term interest rates improved through the adoption of Taylor type rules and likely increased the transparency of Federal Reserve operations. ${ }^{8}$

\subsection{The Minimum Distance and Interest Rates}

It is also possible to characterize the distance from the Taylor curve in terms of the behavior of interest rates. Figure 3 displays the interest rates for the entire sample period. Notice the change in the behavior of short term interest rates approximately beginning in 1915. Mankiw and Miron $(1986,1991)$ provide evidence which suggests that the establishment of the Federal Reserve changed the time-series properties of short-term interest rates. In particular, it is argued

\footnotetext{
${ }^{8} \mathrm{We}$ also performed the analysis for the post-WWII period using the real-time data set constructed in Enders and Bunzel (2010). The results are available in the Unpublished Appendix to this paper.
} 
that the behavior of interest rates changed from being mean reverting to being characterized as unit-root processes. As such, from 1915-1979 short-term interest rates became less predictable. Goodfriend (1991) argues that this change in the nature of short-term interest rates was required in order for the Federal Reserve to achieve their mandate. In order to affect changes in employment and price levels, policy makers needed to be able to exert significance influence over long-term interest rates. In order to affect the long-end of the yield curve persistent shortterm rates are required. Thus, the monetary policy changes in the early 1980s had two positive effects. First, interest rates became more predictable due to increased transparency and the adoption of Taylor type rules; second, interest rate smoothing became a prevalent practice which maintained the persistence needed to affect long-term rates.

Two general observations regarding the series in Figure 2 merit mentioning. First, during time periods in which interest rates were predictable--whether because of mean reverting characteristics (1875 -1914), interest rate pegs due to wars (1914-1920, late1930s - 1945), or increased transparency (1980 - present)--the economy tends to operate close to its efficiency frontier. Second, the time periods in which the position of the economy relative to its Taylor curve is most volatile can be characterized as a period of relatively easy monetary policy (such as the 1920s, post-WWII, and 1970s).

\section{Shifts in the Taylor Curve}

Thus far we have only gauged monetary policy by the distance of the economy from the Taylor curve. However, as suggested by the Lucas critique, changes in monetary policy itself can influence the estimated position and shape of the Taylor curve. Moreover, long-term changes in the underlying volatility of supply shocks (such as oil price shocks) could also shift the Taylor curve. To examine the extent to which the Taylor curve changed over time, we use the 
methodology outlined in Section 3.2 and Section 3.3 and, in Figure 4, we report the orthogonal distance of the estimated Taylor curves from the origin. The solid line in the figure is the smoothed distance from the origin (using a \pm 2 -quarter moving average) and the dashed line is the orthogonal distance of the actual volatilities from the origin. As such, the vertical difference between the two lines is the orthogonal distance measure shown in Figure 2.

In the early part of the sample, the orthogonal distance of the Taylor curve from the origin falls slightly and then jumps following WWI. The most notable feature of the figure is the steady decline beginning in the early 1950s. Except for a small run-up in the mid-1960s, the Taylor curve continually falls throughout the remainder of the sample.

In Figure 5, we report Taylor curves estimated for the following four time periods: 18751913, 1919-1940, 1951-1979, and 1983-2009Q3. The four panels of Figure 5 display the resulting Taylor curves. Before proceeding, it is important to point out the difference in the scales for each of the Taylor curves in Figure 5. It is also important to note that the Taylor curve estimated for the inter-war period 1919 - 1940 is constructed using far fewer observations than the distance values shown in Figures 2 and 3. Nevertheless, it does appear that the Taylor curve clearly shifted outward during the inter-war period relative to the Taylor curve derived for the gold standard period. Hence, it is likely that the overall economic instability of the inter-war period shifted-out the Taylor curve. As evidenced by the large distance between the solid and dashed lines shown in Figure 4, the general climate of economic instability was reinforced by the very loose monetary policies of the 1920s. However, the most striking feature of Figure 4 is the inward shift of the Taylor curve beginning a few years after WWII. This shift is about as large as the subsequent inward shift corresponding to the Great Moderation. Interestingly, not only has 
the Taylor curve shifted toward the origin, since the mid-1980s the efficiency of monetary policy has improved in that the discrepancy from the Taylor curve has shrunk.

The curvature of the Taylor curve is of interest as well. The differing scales on the vertical axes in the four panels in Figure 5 should make it clear that the Taylor curve has actually became flatter through time. The implication is that the opportunity cost of stabilizing inflation in terms of output volatility has declined. Note that the "flattest" Taylor curve corresponds to the time period in which $\lambda$ was likely greatest. As such, the evidence suggests that the recent era of relatively low inflation results from the Taylor curve lying close to the origin and from the decreased cost of reducing inflation.

\section{Conclusion}

We follow Taylor (1979) and Friedman's (2006) suggestion and view the Taylor curve as an efficiency locus showing the trade-off between the variance of output and the variance of inflation. Since monetary policy need not be optimal, it is possible to observe persistent departures from the Taylor curve. Using a long historical data set for the United States, we empirically measure the orthogonal distance of the observed volatilities from the Taylor curve using a rolling window. We find that the distance from the Taylor curve was reasonably constant during the gold standard and steadily rose throughout the 1920s. After the onset of the Great Depression, the distance fell quite sharply and remained at historical lows until 1944. Although the economy remained far from the Taylor curve following WWII, from the mid-1950s to the build-up of the Viet Nam War and the start of the Great Inflation. The distance fell throughout the early 1980 s and has remained fairly constant beginning with the period identified as the Great Moderation. Interestingly, the point estimate of our distance measure during the Great Moderation is about the same as that during the Gold Standard period. The evidence is 
such that our measure of the distance from the Taylor curve is small during periods in which monetary policy is generally deemed to be most satisfactory. Nevertheless, the estimated position of the Taylor curve is not immutable over time. We find that the orthogonal distance of the Taylor from the origin is reasonably stable until the 1950s. Thereafter, the position of the Taylor curve falls to such an extent that the earlier distance measures are more than four times those for the more recent periods. In addition, the shape of the Taylor curve has shifted so that the opportunity cost of reducing inflation variability (in terms of output variability) is very low.

Before concluding, the reader should be aware that our methodology does have some limitations. We use a simple near-VAR to capture the time-series properties of output and inflation without controlling for a number of important sources of external shocks (e.g., wars, oil price shocks, and financial crises). Unlike the time-series models of Dolado, Maria-Dolores, and Naveira (2005) and Bunzel and Enders (2010), we assume the central bank has a simple timeinvariant quadratic loss function. In contrast to DSGE models attempting to quantify optimal monetary policy, such as that by Ravenna (2009), we impose no structural restrictions on the VAR. We defend these limitations as an attempt to estimate the efficacy of monetary policy by imposing as few restrictions on the data as possible. In spite of these limitations, our estimated Taylor curves and measures of the efficacy of monetary policy do seem to be quite plausible. 


\section{References}

Balke, Nathan and Robert J. Gordon (1986). “Appendix B: Historical Data.' In The American Business Cycle: Continuity and Change, edited by Robert J. Gordon. Chicago: University of Chicago Press. 781-850.

Bunzel, Helle and Walter Enders (2010). "The Taylor Rule and 'Opportunistic' Monetary Policy." Journal of Money, Credit, and Banking 42, 931-49.

Cecchetti, Stephen G., Alfonso Flores-Lagunes, and Stefan Krause. (2006). "Has Monetary Policy Become More Efficient? A Cross-Country Analysis.” Economic Journal 116, 40833.

Chatterjee, Satyajit (2002). "The Taylor Curve and the Unemployment-Inflation Tradeoff." Business Review, Federal Reserve Bank of Philadelphia Third Quarter 2002.

Chow, Gregory C. (1975). Analysis and Control of Dynamic Economic Systems. New York, NY: Wiley.

Clarida, Richard, Jordi Gali, and Mark Gertler. (1997). "Monetary Policy Rules and Macroeconomic Stability: Evidence and Some Theory.” NBER Working Paper No. 6442. . (2000). "Monetary Policy Rules and Macroeconomic Stability: Evidence and Some Theory." Quarterly Journal of Economics 115, 147-180.

- (1999). The Science of Monetary Policy: A New Keynesian Perspective. Journal of Economic Literature 37(4), 1661-1707.

Ericsson, Neil R., and John S. Irons. (1995). "The Lucas Critique in Practice: Theory Without Measurement." Board of Governors of the Federal Reserve System, International Finance Discussion Paper No. 506.

Estrella, Arturo and Jeffrey C. Fuhrer. (1999). “Are "Deep” Parameters Stable? The Lucas Critique as an Empirical Hypothesis." Working Paper 99-4. Federal Reserve Bank of Boston.

Favero, Carlo and David Hendry. (1992). "Testing the Lucas Critique: A Review." Econometric Reviews, 11(3): 265-306.

Friedman, Milton. (2006). "Tradeoffs in Monetary Policy.” Paper presented as Unpublished Manuscript, Stanford University.

Goodfriend, Marvin (1991). "Interest Rates and the Conduct of Monetary Policy." CarnegieRochester Conference Series on Public Policy 34, 7-37. 
Hendry, David. (2000). "Forecast Failure, Expectations Formation, and the Lucas Critique." Unpublished Manuscript, Nuffield College: Oxford.

Lee, J. (2002). "The Inflation-Output Variability Tradeoff and Monetary Policy: Evidence from a GARCH model." Southern Economic Journal, 69. 175-88,

Mankiw, N.Gregory and Jeffrey A. Miron. (1986). "The Changing Behavior of the Term Structure of Interest Rates." Quarterly Journal of Economics 101, 211-228. . (1991). "Should the Fed Smooth Interest Rates? The Case of Seasonal Monetary Policy.” NBER Working Paper No. 3388.

and David N. Weil. (1987). "The Adjustment of Expectations to a Change in Regime: A Study of the Founding of the Federal Reserve." The American Economic Review 77(3), 358-374.

Mishkin, Federic and Klaus Schmidt-Hebbel. (2007). "Does Inflation Targeting Make a Difference?” NBER Working Paper No. 12876.

Olson, Eric, Walter Enders, and Mark Wohar. (2012). "An Empirical Investigation of the Taylor Curve." Journal of Macroeconomics. forthcoming.

Orphanides, Athanasios. (2003). "Historical Monetary Policy Analysis and the Taylor Rule." Journal of Monetary Economics 50(5), 983-1022.

Ravenna, Federico (2010). "Optimal Policy Restrictions on Observable Outcomes.” Unpublished Manuscript, HEC Montreal.

Rudebusch, Glenn D. (2002). "Term Structure Evidence on Interest Rate Smoothing and Monetary Policy Inertia." Journal of Monetary Economics 49, 1161-1187.

Taylor, John B. (1979). "Estimation and Control of a Macroeconomic Model with Rational Expectations." Econometrica 47(5), 1267-86.

_. (1998). "A Historical Analysis of Monetary Policy Rules," in John B. Taylor Monetary Policy Rules, Chicago: University of Chicago Press, 319-340.

—. (2006). "Comments on 'Tradeoffs in Monetary Policy' by Milton Friedman." Unpublished Manuscript, Stanford University.

Woodford, Michael (1999). “Optimal Monetary Policy Inertia.” NBER Working Paper 7261. http://www.nber.org/papers/w7261. (Last accessed December 12, 2011).

. (2003). Interest and Prices: Foundations of a Theory of Monetary Policy. Princeton: Princeton University Press. 


\section{Figure 1}

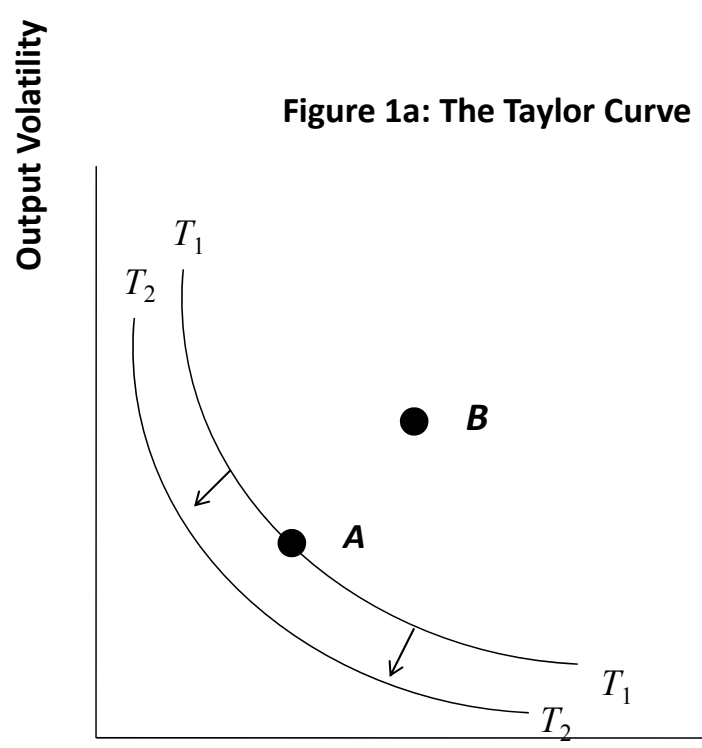

Inflation Volatility

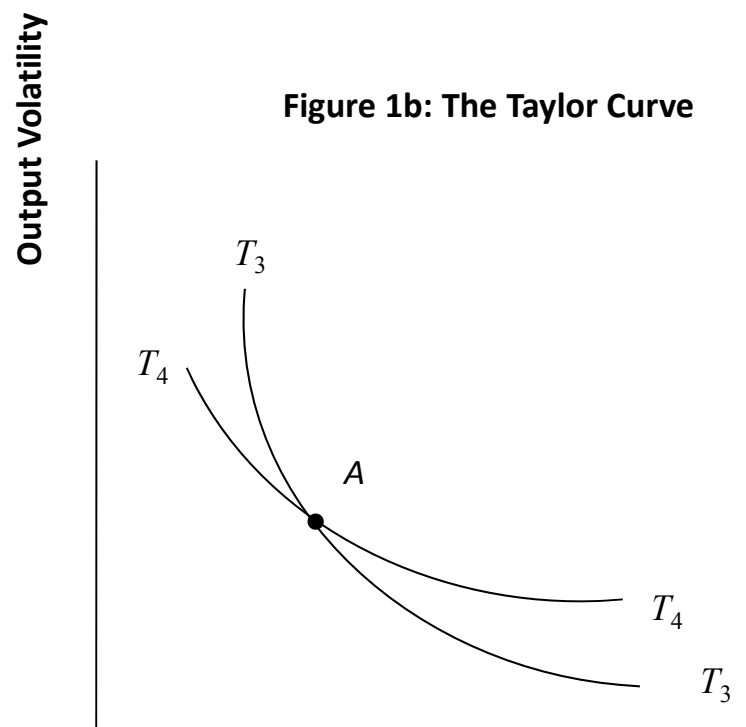

Inflation Volatility 
Figure 2

\section{Distance from the Taylor Curve}

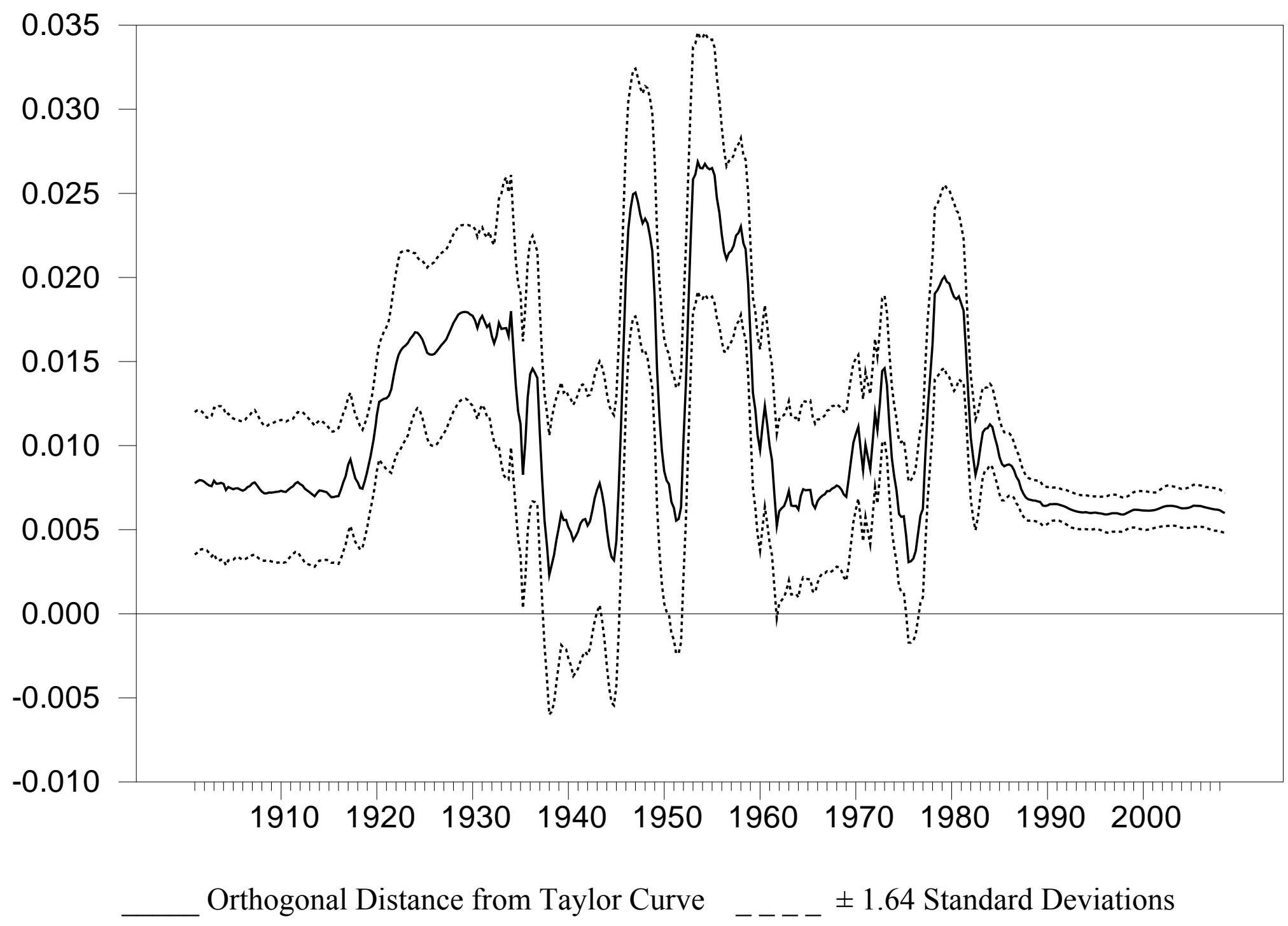


Figure 3

Interest Rates: 1875 - 2009

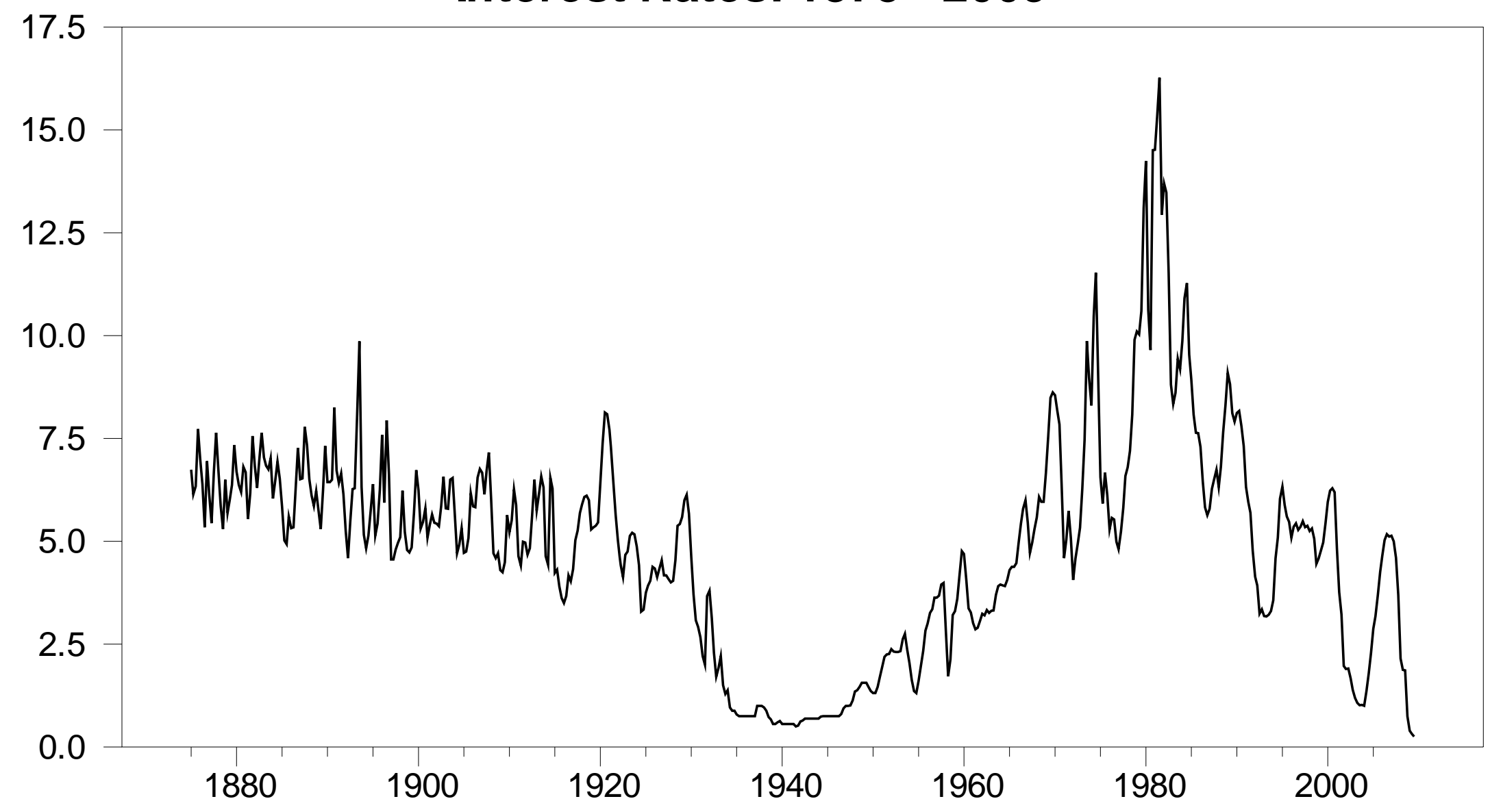


Figure 4

\section{Distance of the Taylor Curve From the Origin}

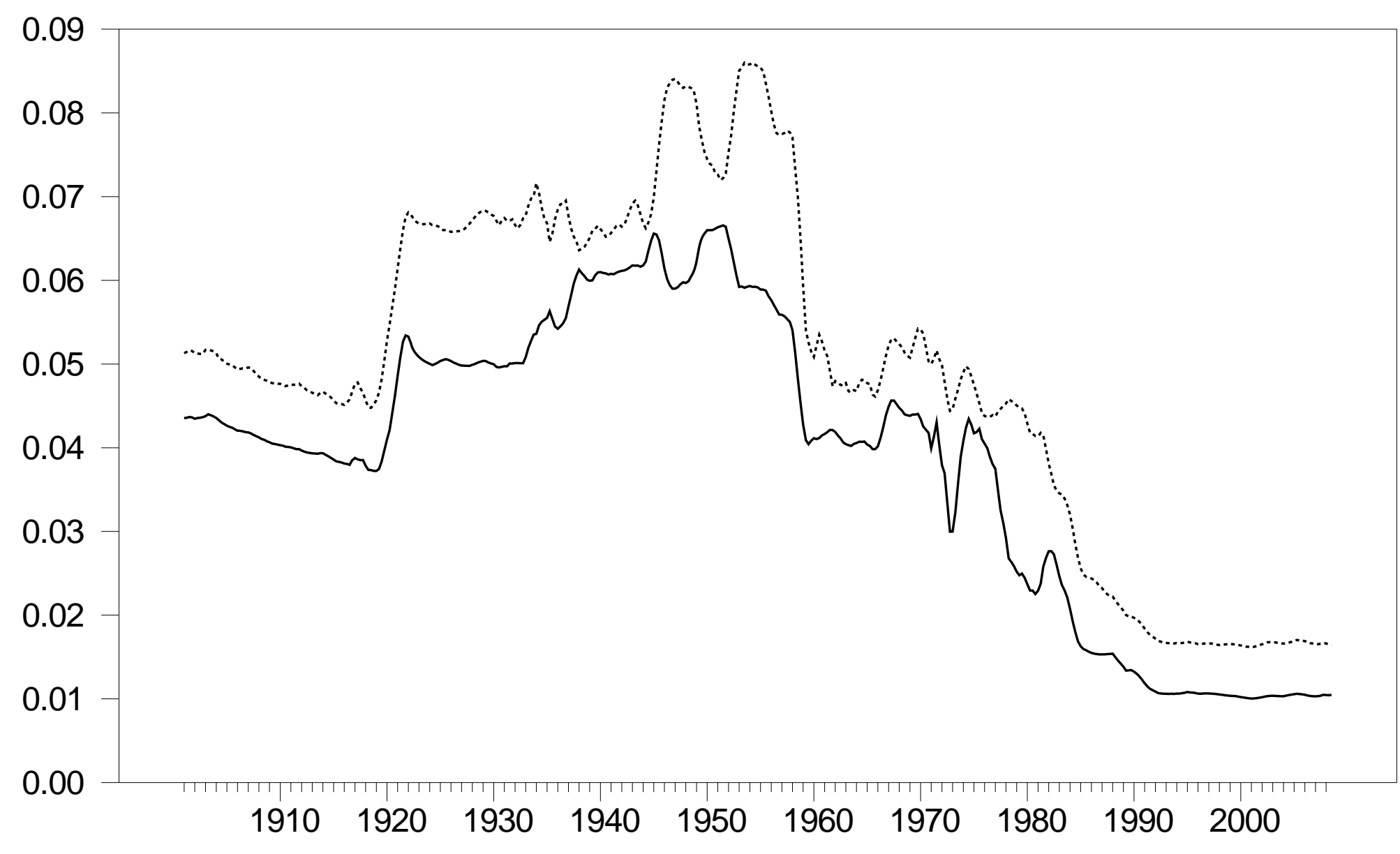

Distance of the Taylor Curve from Origin Distance of the Standard Deviations 


\section{Figure 5}

\section{Taylor Curves}
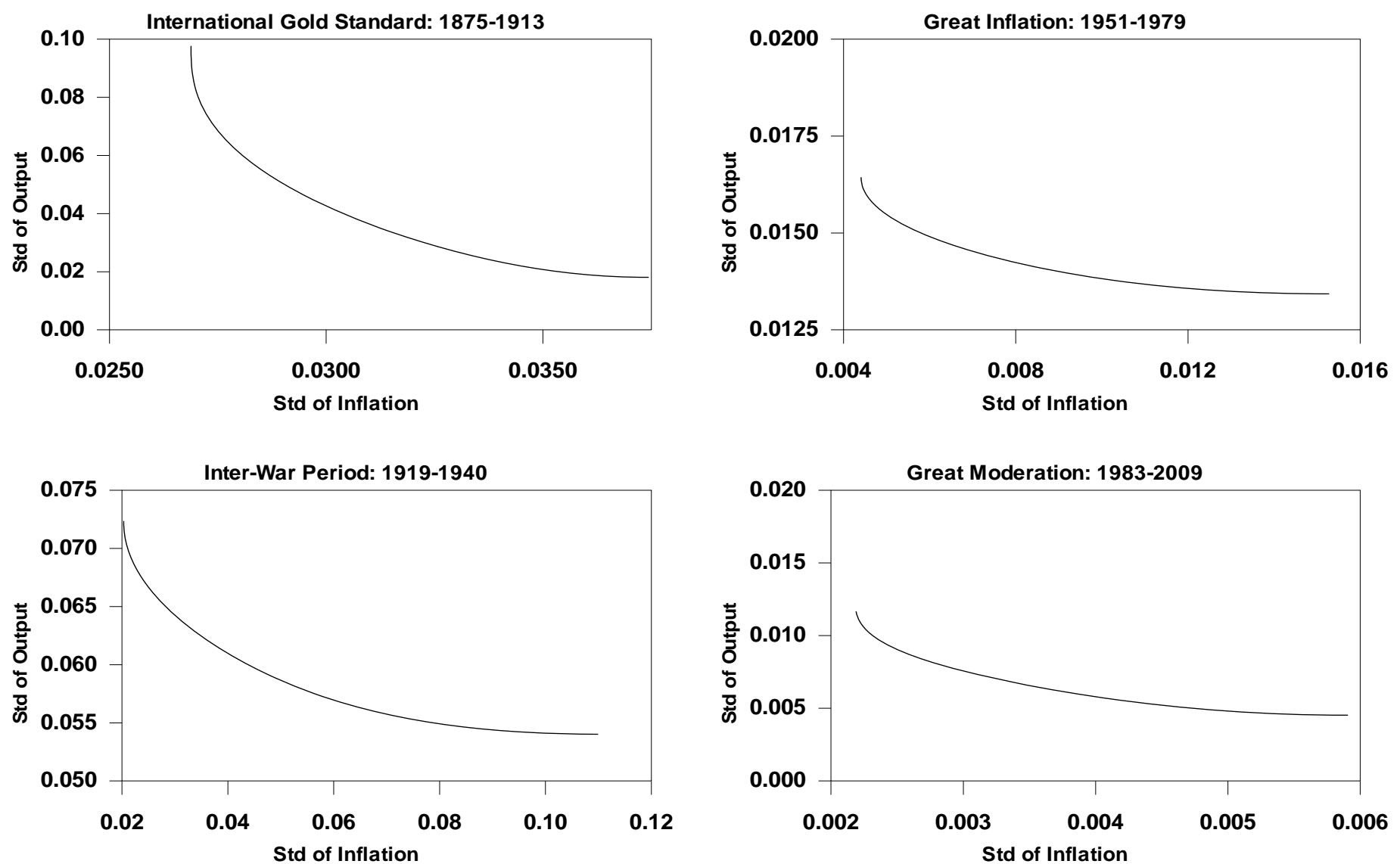